displayed in selling the liniment without a poison label, and the tendency of some chemists to neglect that and other precautions in the sale of poison calls for immediate attention. Aconite liniment and belladonna liniment are both poisons within the meaning of the Pharmacy Act, and consequently they cannot lawfully be sold by registered chemists, unless distinctly labelled with the words "poison," and the name of the article, etc. Aconite liniment being in the first part of the poison schedule as one of the more dangerous poisons, its sale has to be accompanied by further precautions. The person to whom it is supplied must be known to the seller or introduced by a person known to him. The sale must be registered in a book kept for that purpose, with a statement of the date, name, and address of purchaser, name and quantity of article supplied, purposes for which it is required, and this entry of particulars must be attested by the signature of the purchaser or that of the person introducing him to the chemist. If these regulations are observed as strictly as they require to be, the difficulty of obtaining any of the articles included in the first part of the poison schedule will sufficiently impress people with a sense of their dangerous character to induce caution in their use and prevent accident. But there is reason for doubting whether the regulations are attended to by chemists in such a manner as to protect the public or even to justify the restriction of the sale of poisons to registered chemists. Many are of opinion, therefore, that entire freedom of sale, subject to very stringent provisions as to the use of a conspicuous poison label or some other mechanical safeguard would be more effectual in preventing accidental poisoning. However that may be, there is evidently need for a more strict control of the supply of poisons by registered chemists than is always exercised by them. In the case now referred to the chemist had evidently neglected either to label the bottle, to register the sale, or to enter the supply of the poisonous article in the prescription book. When the child was poisoned there was, therefore, no means of ascertaining the nature of the poison, and the chemist had then forgotten whether the liniment was aconite or belladonna. We cannot understand the disinclination of chemists to adhere to the regulations laid down in the Act, but would suggest that if such negligence as the above case exhibits is met with it is the business of the Pharmaceutical Society to exercise its powers under the Act upon all offenders, whether they be chemists or grocers.

DISTOMA RINGERI IN AMERICA.

THE discovery by Professor Ward, University of Nebraska, that distoma Ringeri (D. Westermanni, Kerbert) occurs in the United States of America, is of medical as well as of scientific interest. Hitherto this parasite has been found only in Japan, Corea, and Formosa, where it is the cause of a peculiar form of hæmoptysis and chronic cough, with rusty mucoid expectoration, in a considerable proportion of the population in certain districts. It is now known that this fluke lives in the lungs in burrows or cysts which communicate with the bronchi. The discharge from these cysts constitutes the characteristic sputum of the disease, and contains the rusty brown ova of the parasite. Kerbert in 1878 found the same parasite in the lungs of a tiger, and Raillet refers to its occurrence in the dog in Japan. Professor Ward has now found it in the lungs of the cat in America. It would be interesting to know if the parasite is indigenous to the United States, and the exact areas and localities of its distribution; or, as is more probable, if it is of recent introduction (probably from Japan), and, if so, in what way and when it was introduced. It would also be interesting to know the history of the cat in whose lungs the parasite was found. Was it born and had it always lived in the United States? If distoma Ringeri is now endemic in Anerica we may expect to hear more about it soon, not only as a parasite of the lower animals but as a cause of endemic hæmoptysis in man. The figure Dr. Stiles gives 1 of an ov um of the parasite is somewhat misleading. When newly expectorated the ova do not contain a ciliated embryo as represented; it is only after they have lain in water for a month or two that the embryo is developed.

\section{THE PRACTICES OF QUACKS.}

COLLECTIVE INVESTIGATION.

\section{A PROPOSAL BY THE CHAIRMAN OF THE PARLIA-} MENTARY BILLS COMMITTEE.

A conRespondent from Haslingden, Lancashire, has forwarded a flyleaf advertisement of a herbalist, in which the advertiser states that he has no rival among the myriad herbalists of the kingdom; it is one of many similar documents which reach mefrom time to time. There is nodoubt that this class of quacks is very large, and does an immense amount of harm. These charlatans defraud the public of their money and injure them in health. The Legislature does nothing. To a great extent this apathetic indifference of the powers that be is due to an utter ignorance of the magnitude of the evil. Members of the profession dilate eloq uently on the number of these pests and the evils they perpetrate. But such general denunciation does not lead to much practical result. If the Chairman of the Parliamentary Bills Committee of the Association is to take the matter in hand, he must be in a position to present a strong case. On the strength of the case that he can bring forward the possibility of future legislation must depend. The information must be reliable and well digested. It would be necessary for this purpose for every Branch to divide itself into districts. The members practising in each district must take different localities. Each member must collect the following information: The name and address of the quack, the description of his premises, one of his advertisements, including a copy of each book and pamphlet, and cuttings from the local papers with dates; a memorandum must also be made of the date on which the name, address, and description of the premises is taken down. The member must do this himself, and preserve his original notes. The results of the observations should then be catalogued and arranged by the different Branches. It would also be necessary to note the nature and condition of the neighbourhood where the quack purports to practise, and his hours of attendance. If this work is carried on all through the United Kingdom, we should then be in a position to call the attention of Parliament to the prevalence of quackery. I admit that the task is a heavy one, but unless some such plan is carried out it will be impossible to expect such drastic reform in the Medical Acts as is desirable in the public interests as well as in the interest of the profession. This class of quacks will scarcely be affected by the hitherto proposed amendments to the Medical Acts.

Ernest Hart.

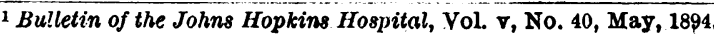

